\title{
Obtaining an Optical Trap Type Surface by Plasma Electrolytic Oxidation
}

\author{
Hugo Fernandes Medeiros da Silva ${ }^{a} \mathbb{D}$, Tarciana Dieb Toscano ${ }^{b}$, Kelly Cristiane Gomes ${ }^{c}$,
}

\author{
José Felix da Silva Neto ${ }^{c}$, Francine Alves da Costa ${ }^{a}$,Clodomiro Alves Junior ${ }^{b}$
}

${ }^{a}$ Departamento de Engenharia Mecânica Campus, BR101, s/n, 59072-970, Lagoa Nova Natal, RN, Brasil

${ }^{b}$ Centro das Engenharias, Universidade Federal Rural do Semi-Arido, Pres. Costa e Silva, 59625-900, Mossoró, RN, Brasil

'Departamento de Engenharia de Energias Renováveis, Universidade Federal da Paraiba, Cidade universitária, s/n, Campus I, Castelo Branco, 58051900, João Pessoa, PB, Brasil

Received: July 06, 2017; Revised: January 25, 2018; Accepted: February 01, 2018

\begin{abstract}
High performance solar collectors are those with high selectivity surfaces, high solar radiation absorption and that do not thermally reemit to the external environment. Strategies to enhance this performance might involve surface porosity modification. In this work, a plasma treatment technique called plasma electrolytic oxidation (PEO) has been tested to produce porosity on aluminium surfaces in a controlled manner. The porosity control was made by varying the intensity, frequency and duty cycle of the applied voltage pulses. The aluminium sample was placed in a solution of $1 \mathrm{~g} / \mathrm{L} \mathrm{Na}_{2} \mathrm{SiO}_{3}$. Voltage of $500 \mathrm{~V}$ and current density of $0.17 \mathrm{~A} \mathrm{~cm}^{2}$ was applied between electrodes. Three duty cycles were used: $33.33 \%, 50.00 \%$ and $67.77 \%$. After treatment, the size, number and distribution of pores were evaluated. These parameters were correlated with both surface reflectance and optical absorbance. It was possible to control the porosity by controlling the electrical parameters of the process. While the mean pore size was directly related to the duty cycle, the inverse occurred for the number of pores. Surface treated with duty cycle of $33.33 \%$ presented higher values of absorption for all wavelength range.
\end{abstract}

Keywords: $P E O$, pulsed, duty cycle, optical trap.

\section{Introduction}

Environmental problems and energy crises have occurred around the world, requiring the exploration of new energy sources. Solar energy, especially in areas where the incidence is abundant, is shown as the most promising because it is renewable and virtually inexhaustible ${ }^{1}$. One way to use this energy source is by converting solar radiation to thermal radiation ${ }^{2,3}$. When this conversion is done by the use of solar collectors ${ }^{4,5}$, solar radiation is absorbed at the surface. Similarly, the transfer of this radiation in the form of heat to a fluid happens. Therefore, it is necessary that the collectors have good absorbance of the solar spectrum and low emissivity in the infrared, to ensure that this energy conversion is more efficient on the surface ${ }^{2}$. Whereas the radiation absorption is a phenomenon which occurs on the surfaces of materials, many techniques and types of surfaces are being studied for producing such collectors. This type of desired surface is known as the selective surface ${ }^{6}$. Among the existing processes to increase the optical selectivity of the surface, we highlight the electrodeposition, laser deposition, Sputtering ${ }^{7}$ and wet methods ${ }^{8}$. However, many of these methods consist of expensive processes involving high temperatures and vacuum. In other cases, they are

*e-mail: hugofernandes20@hotmail.com considered inefficient, such as the technique based on the submerging of substrate into ink to form a film. In addition, they can also harm the environment, such as chemical conversion ${ }^{9}$. The plasma electrolytic oxidation - PEO, is a technology that has been used in the production of oxides of light metals such as $\mathrm{Al}, \mathrm{Mg}$, Ti, etc. ${ }^{10-13}$. The process is based on the combination of effects of conventional electrolysis and atmospheric plasma generated around the immersed sample in an aqueous solution. In this process, the substrate will be used as anode. When a voltage is applied between a stainless-steel electrode (cathode) and the anode (sample), it is covered by its own oxide because of the conventional oxidation process. Then, this layer behaves like a dielectric barrier, making it difficult for electrons to pass by the system and increasing the voltage. When the voltage increases, the breakdown of the dielectric strength occurs in this layer. That causes extremely high electronic temperatures (around $2 \times 10^{4} \mathrm{C}$ ) in this region, and pressures of about $2 \times 10^{2}$ $\mathrm{MPa}^{14}$. When this occurs, numerous short duration micro discharges arise, causing effects such as diffusion of material and heating. This heating is generated by the micro melting of the substrate and the depletion of molten material. This molten material is released out of the substrate through the channels where the discharges occur. This melt is rapidly 
cooled by the electrolyte, increasing the effectiveness of the reaction with the electrolyte ${ }^{10,13,14}$. Surfaces formed by this technique can be controlled by varying both the composition of the electrolyte as well as the electrical parameters used in the power supply ${ }^{14}$.

In the present work, a pulsed voltage power supply was used in PEO technique to control the surface porosity during treatment of aluminum substrates. The ratio between ON time and total period, defined as duty cycle, was used as process parameter. The objective of this study was to correlate the morphological characteristics of the surface with the optical characteristics (absorbance and reflectance) obtained.

\section{Materials and Methods}

\subsection{Preparation of the samples}

Aluminium disks $29,5 \times 10^{3} \mu \mathrm{m} \times 3 \times 10^{3} \mu \mathrm{m}$ (diameter $\mathrm{x}$ thickness) were produced from billets with the same diameters. Then they were embedded with polyester resin, the inner part being fixed to copper wire to serve as contact. The outer part was polished to a particle size of $0.05 \mu \mathrm{m}$ the polished substrates were washed in an ultrasonic bath using enzymatic detergent for $660 \mathrm{~s}$ for degreasing and cleaning. After drying, the substrates were placed in a solution of sodium silicate $\left(\mathrm{Na}_{2} \mathrm{SiO}_{3}\right)$ at a concentration of $1 \mathrm{~g} / \mathrm{L}$. For each treatment $0.5 \mathrm{~L}$ of solution was used. The electrolyte solution was changed with each new test so that the conditions of equality were guaranteed.

\subsection{Plasma electrolytic oxidation}

Each treatment lasted $900 \mathrm{~s}$, in the same current and voltage, $500 \mathrm{~V}$ and $0.5 \mathrm{~A}$, respectively, resulting in a current density of $0.17 \mathrm{~A} / \mathrm{cm}^{2}$. Three different duty cycles, $33.33 \%$, $50.00 \%$ and $67.77 \%$, corresponding to the $\mathrm{T}_{\text {on }}, \mathrm{T}_{\text {off }}$ ratios of 50 , $100,100,100$ and 100, 50, respectively, were used. Samples were represented by the notation $\mathrm{T}_{\text {on, off }}$ The experimental apparatus used to perform the treatments consists mainly of a pulsed high voltage source (maximum voltage of 700 $\mathrm{V}$ and power of $5000 \mathrm{~W}$ ) connected to an electrolytic cell (Figure 1).

\subsection{Surface characterization}

After the treatment, the samples were analyzed by X-ray diffraction model XRC-6000, Shimadzu, using grazing incidence (0.5 degree) and scanning electron microscope, model VEGA3, TESCAN. The micrographs obtained were then processed and analyzed using the ImageJ $1.51 \mathrm{j} 8$ software. Initially, an area of $2500 \mu \mathrm{m}^{2}$ of each image was determined. This reduced area was used to minimize the number of errors in the acquisition and count of pores. Then, to quantify the porosity, the following algorithm was used: Sigma Filter Plus filter and threshold. These processes consist of image segmentation, which is based on the difference in gray levels that make up different objects in an image. For each sample,

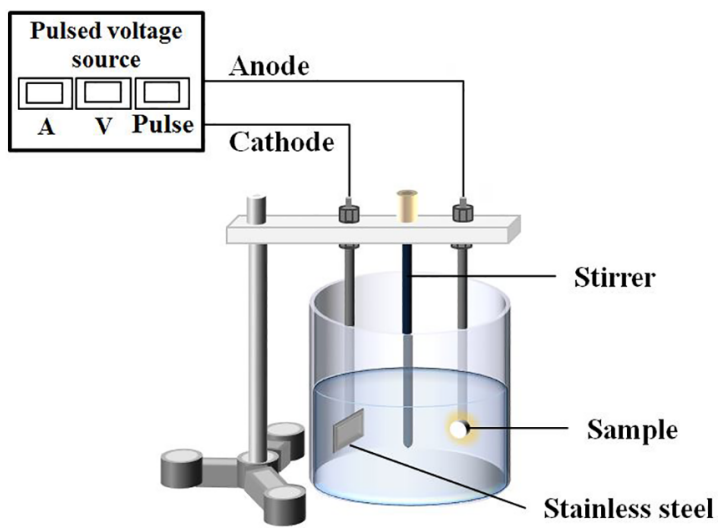

Figure 1. Schematic model of the experimental apparatus used for electrolytic treatment

a micrograph was analyzed and the image processing was done as proposed in the literature ${ }^{15}$.

Water droplets were placed on the surfaces of the samples and the absorption time was determined to estimate the volume of interconnected pores. Knowing the volume of the semi-spherical shell produced by the drop between two consecutive instants $i$ and $f$, it was possible to estimate the volume absorbed by the surface applying the difference of (Eq. (1)).

$$
V_{c a p}=\frac{1}{6} \pi h\left[3\left(a_{i}^{2}-a_{f}^{2}\right)+\left(h_{f}^{2}-h_{i}^{2}\right)\right]
$$

Where $a$ is the radius of the drop and $h$ is the height in two consecutive instants $i$ and $f$.

Three measurements were performed for each sample. The droplets had a known volume of $7.5 \mu \mathrm{L}$. Knowing the radius and height of the hemispherical cap for different instants, the absorption rate and the total volume absorbed by the sample were determined. The latter was determined only $25 \mathrm{~s}$ after complete accommodation of the drop (Figure 2 ). With this, the interconnected porosity of each sample was estimated.

To determination of the optical absorption, an UV-Vis Spectrophotometer UV-2550, Shimadzu was used. Initially, the reflectance in the radiation range of $0.225 \mathrm{~nm}$ to 0.825 $\mathrm{nm}$ was measured using an integrating sphere to quantify the diffuse radiation. Considering that the entire radiation incident on the samples is reflected or absorbed, the spectral absorbance plot of the samples can be constructed from the reflectance.

\section{Results and Discussion}

Initially, the crystallographic analysis was performed in order to show the presence of the crystalline structure related to the compound present on the formed layer, analyzes were performed by grazing incidence X-ray diffraction in the treated samples as well as in the untreated Al plate. Aluminium oxide 


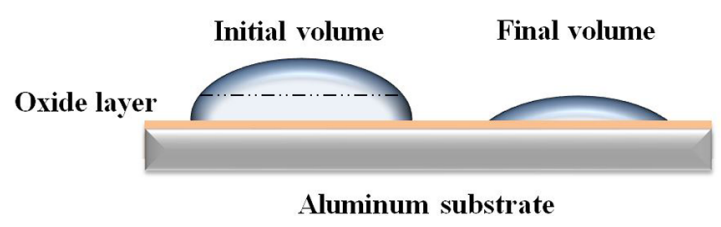

Figure 2. Schematic model of the volume variation of the semispherical cap produced by the drop by the action of the absorption of part of the volume

was the only phase present after treatment by electrolytic plasma (figure 3), besides the aluminium substrate.

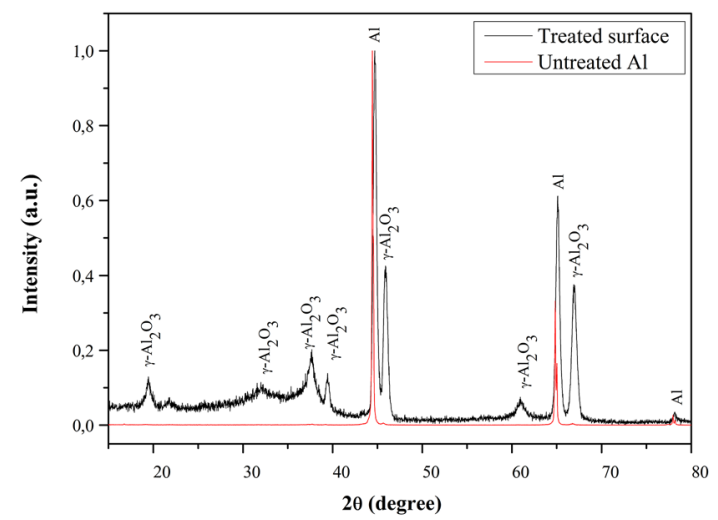

Figure 3. X-ray diffraction, grazing incidence, of the surface sample after electrolytic plasma treatment, and the untreated $\mathrm{Al}$

After this, the samples were analyzed by SEM. Micrographs with 2000x magnification were obtained to the samples, polished aluminium, $\mathrm{T}_{50,100}, \mathrm{~T}_{100,100}$ and $\mathrm{T}_{100 \text {, }}$ ${ }_{50}$, respectively. Then this micrographs were treated with threshold (Figure 4) using ImageJ.

The mean size and number of pores were obtained for an area of $2500 \mu \mathrm{m}^{2}$ (Table 1). It is observed that there is a direct relationship between duty cycle and pore size, but an inverse relationship with pore density. A possible explanation for this result may be associated with the $T_{\text {on }}$ (pulse width) and the $\mathrm{T}_{\text {off }}$ (pulse repetition time). The pore size or micro melting intensity in the substrate is proportional to the heating $\left(\mathrm{T}_{\text {on }}\right)$ and cooling $\left(\mathrm{T}_{\text {off }}\right)$ time. If $\left(\mathrm{T}_{\text {off }}\right)$ is greater than

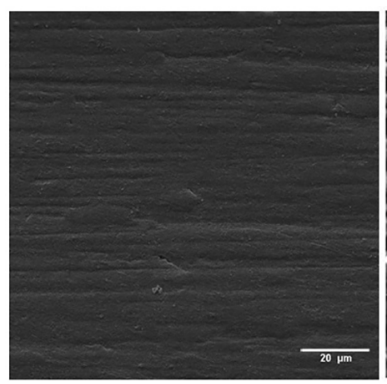

A

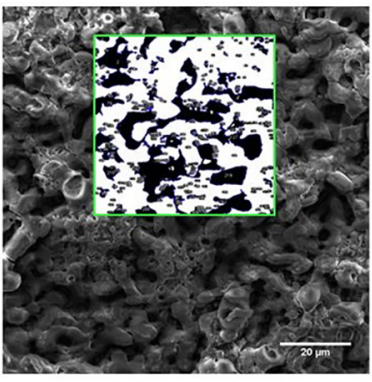

B

$\left(\mathrm{T}_{\mathrm{on}}\right)$, there will be little removal of molten material due to cooling of the substrate during the $\left(\mathrm{T}_{\text {off }}\right)$ and the pore will be smaller. Thus, one can control the size and distribution of pores by changing the $\left(\mathrm{T}_{\text {on }} / \mathrm{T}_{\text {off }}\right)$ ratio.

Table 1. Size and number of pore in area of $2500 \mu \mathrm{m}^{2}$ of the sample surface plasma treated.

\begin{tabular}{lccc}
\hline Sample & Duty cycle & $\begin{array}{c}\text { Mean size } \\
(\mu \mathrm{m})\end{array}$ & Pores number \\
\hline $\mathrm{T}_{50,100}$ & $33.33 \%$ & 2.56 & 317 \\
$\mathrm{~T}_{100,100}$ & $50.00 \%$ & 5.03 & 134 \\
$\mathrm{~T}_{100,50}$ & $66.67 \%$ & 10.63 & 57 \\
\hline
\end{tabular}

By the image analysis it was also possible to obtain the distribution curves of pore size (Figure 5). It is verified that the sample treated at $\mathrm{T}_{50,100}$ has $21.67 \%$ of its total porosity within the limit wavelength range detected by the spectrophotometer, while the samples prepared at T100, 100 and $\mathrm{T}_{100,50}$ have, respectively, $9.7 \%$ and $36.86 \%$. Although $\mathrm{T}_{100,50}$ has a higher percentage of its pores in this range, it may not be as efficient as a selective surface, because of its low pore density in this range, and with this, probably less occurrence of optical trap effect. In this case, the best among the 3 different duty cycles would be the $\mathrm{T}_{50,100}$, has a good percentage of pores in the range of desired porosity, in addition, a higher density of pores.

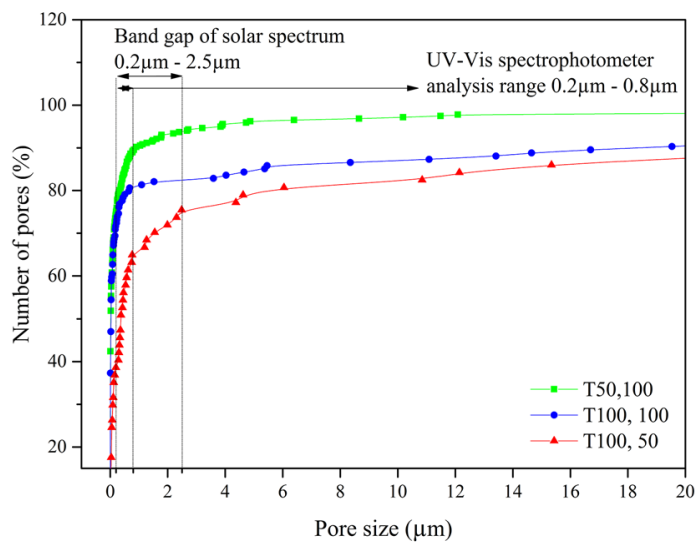

Figure 5. Accumulated percentage distribution of pore size for an area of $2500 \mu \mathrm{m}^{2}$ highlighted in figure 4

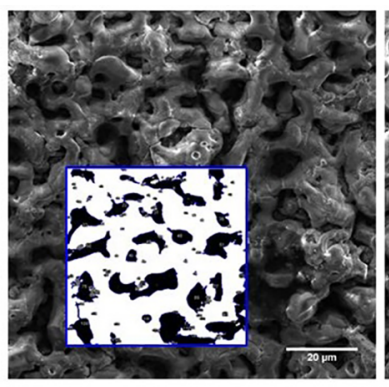

C

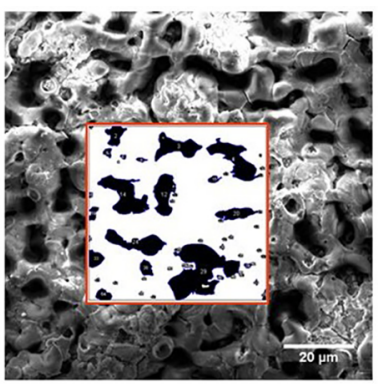

D

Figure 4. Scanning electron microcopy images and respective thresholds (highlighted) with a 2000x magnification, for the samples (A) untreated Al, (B) $\mathrm{T}_{50,100} ;$ (C) $\mathrm{T}_{100,100}$ e (D) $\mathrm{T}_{100,50}$ 
Then, this result could be compared with the volume variation of the hemispheric cap produced by a drop, which relates to the amount of water that was absorbed in each sample. It was observed that the liquid absorption depends on the amount of pores on the surface of the sample. For the sample, $\mathrm{T}_{50,100}$ which had higher amount of pores, presented higher absorption. As expected, the $\mathrm{T}_{100,100}$ e $\mathrm{T}_{100,50}$, where the number of pores decreases (Table 1 ), the absorption of the liquid also decreases (Figure 6). This behavior was attributed to the fact that the samples with greater number of pores, because they have a larger specific free surface, end up absorbing more liquid on its surface. Moreover, the relationship between the number of pores, suggests that the pore count performed by the algorithm used in the ImageJ software is efficient.

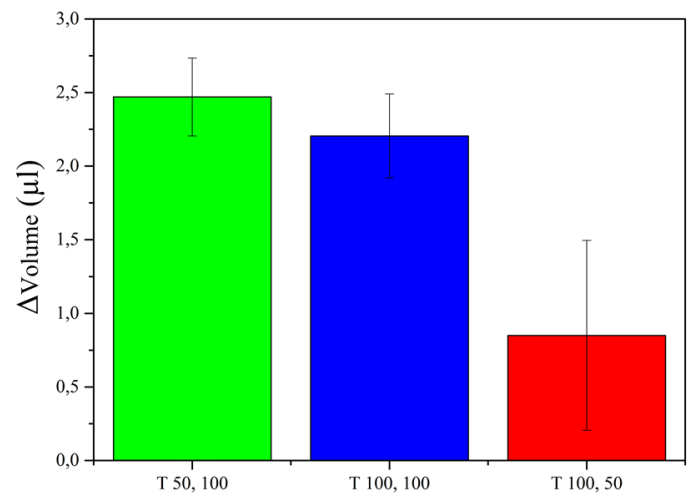

Figure 6. Measurement of drop absorption using the volume method of the semi-spherical cap

To elucidate the results, spectral reflectance analyzes were performed on the plasma treated samples and compared to the untreated surface of the polished substrate. As expected, all plasma-treated samples became optically selective (Figure 7). It was found that at wavelengths less than 650 $\mathrm{nm}$, the percentage of reflected light was lower than that of polished aluminium. For surfaces with a mean pore size of $10.63 \mu \mathrm{m}$, the percentage of reflectance was slightly higher than the others. The surfaces with a pore size of $2.53 \mu \mathrm{m}$ were the ones with the lowest reflectance in the visible range, but for the UV radiation range it was similar to the surfaces with a mean pore size of $5.03 \mu \mathrm{m}$.

Another important result that must be observed is the absorbance of the incident radiation. We know that metals have the ability to shine when polished. This brilliant appearance is a consequence of its high reflection coefficient. This is caused by the interaction of light with the free electrons that are present in the metal. Being responsible for reflecting almost $100 \%$ of the light ${ }^{16}$. In addition, materials composed of covalent or ionic bonds, as the surface obtained by the oxidation by electrolytic plasma, are not considered good absorbers. This means that only the radiation associated with more energetic photons can be absorbed by these materials ${ }^{17}$. Therefore, considering the solar spectrum, only the part of

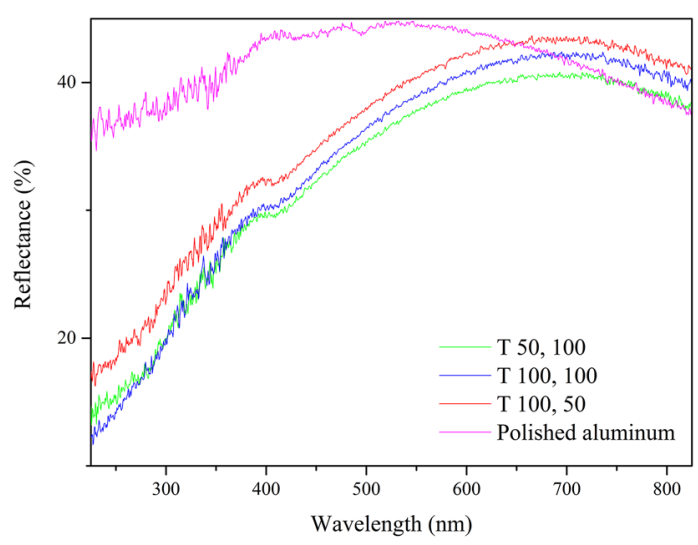

Figure 7. UV-Vis reflectance spectrum of the prepared surfaces under conditions $\mathrm{T}_{50,100}, \mathrm{~T}_{100,100}$ and $\mathrm{T}_{100,50}$ with different size different surfaces

the radiation in the ultraviolet range is absorbed by these types of materials ${ }^{17}$. In the absorbance plot in (Figure 8), as in the graph of reflectance in (Figure 7), the treated samples show better performance than the polished substrate. Consequently, we can affirm that the obtained porous surface plays the function of optical trap ${ }^{18}$. We have seen that the most absorptive surface was produced by the smallest duty cycle $\mathrm{T}_{50,100}$, which exhibited $84 \%$ absorption of light. The sample $\mathrm{T}_{100},{ }_{100}$ absorbed $83 \%$, but in the ultraviolet range showed greater selectivity for this wavelength range. From the samples treated, the sample $\mathrm{T}_{100,50} 80 \%$ absorbed. In contrast, the untreated substrate absorbed only $63 \%$ of the incident light (Figure 8). In the sample $\mathrm{T}_{100,100}$ there was greater selectivity in the ultraviolet region (up to $400 \mathrm{~nm}$ ) compared to the sample $\mathrm{T}_{50,100}$ e $\mathrm{T}_{100,50}$, which had lower absorption in this region. This selectivity may be interesting for other applications, in addition to thermal imaging. As in the production of photovoltaic surfaces, because UV radiation is more efficient in producing electricity. Or even in the production of an intelligent surface, which can always remain sterile, since ultraviolet radiation is considered bactericida $1^{19}$. In addition, the $\mathrm{T}_{100,100}$ and $\mathrm{T}_{100,50}$, presented low absorption in the near infrared band, from $700 \mathrm{~nm}$, being less indicated for the production of solar collectors. However, it is currently needed to obtain surfaces with high reflectance in this range for use in coatings for cold coatings in the control of cooling and heating and in the conditions of interior thermal comfort of buildings ${ }^{20}$. The samples $T_{100,100}$ and $\mathrm{T}_{100,50}$ showed lower absorption in the visible, that goes from $400 \mathrm{~nm}$ to $700 \mathrm{~nm}$, compared to $\mathrm{T}_{50,100}$. However, when compared to the polished sample, its performance is better. Based on these results, we have seen that the application of smaller duty cycles produces pores in greater quantity and with a smaller variation of pore size. Thus, in order to obtain selective surfaces with greater capacity of absorption, and consequently, good absorbers for solar collectors, it was confirmed that PEO using a duty cycle of $33.33 \%$ is the best. 


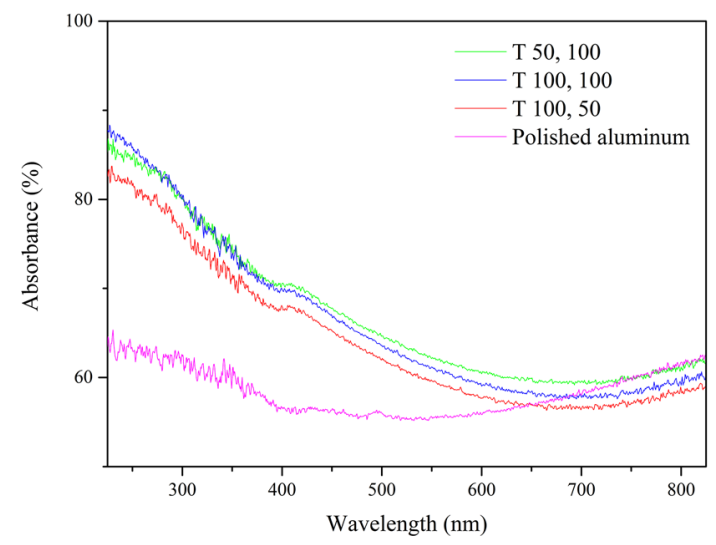

Figure 8. UV-Vis absorption spectrum for samples $T_{50,100}, T_{100,100}$ and $\mathrm{T}_{100,50}$

\section{Conclusions}

According to the cumulative pores distribution and SEM, samples $\mathrm{T}_{50,100}$ and $\mathrm{T}_{100,100}$ presented higher nucleation of smaller pores. However, $\mathrm{T}_{100,50}$ had less pores, with a bigger mean pore size. Therefore, to control the porosity, it can be observed that with the increase of the duty cycle, less pore nucleation occurs, but pore size tends to increase. It is indicated that when duty cycle arise, are obtained a minor number of discharges, but with less intensity. Because lower duty cycle presented a less number of porous in higher amount. Furthermore, were obtained results related to the optical properties which showed us that plasma electrolytic oxidation technique has a great potential to create optical trap selective surfaces.

\section{Acknowledgments}

We thank CAPES and CNPq development agencies for financial support.

\section{Referências}

1. Thirugnanasambandam M, Iniyan S, Goic R. A review of solar thermal technologies. Renewable and Sustainable Energy Reviews. 2010;14(1):312-322.

2. Gelin K, Boström T, Wäckelgård E. Thermal emittance of sputter deposited infrared reflectors in spectrally selective tandem solar absorbers. Solar Energy. 2004;77(1):115-119.

3. Sathiaraj TS, Thangaraj R, Agnihotri OP. High absorptance and low emittance AR-coated Ni- $\mathrm{Al}_{2} \mathrm{O}_{3}$ solar absorbers. Journal of Physics D: Applied Physics. 1990;23(2):250.

4. Tian Y, Zhao CY. A review of solar collectors and thermal energy storage in solar thermal applications. Applied Energy. 2013;104:538-553.

5. Kalogirou SA. Solar thermal collectors and applications. Progress in Energy and Combustion Science. 2004;30(3):231-295.
6. Bogaerts WF, Lampert CM. Materials for photothermal solar energy conversion. Journal of Materials Science. 1983;18(10):28472875 .

7. McKenzie DR. Production of solar absorbing cermet films by dual cathode d.c. magnetron sputtering. Thin Solid Films. 1979;62(3):317-325.

8. Wijewardane S, Goswami DY. A review on surface control of thermal radiation by paints and coatings for new energy applications. Renewable and Sustainable Energy Reviews. 2012;16(4):1863-1873.

9. Granqvist CG. Preparation of thin films and nanostructured coatings for clean tech applications: A primer. Solar Energy Materials and Solar Cells. 2012;99:166-175.

10. Yerokhin AL, Nieb X, Leyland A, Matthews A, Dowey SJ. Plasma electrolysis for surface engineering. Surface and Coatings Technology. 1999;122(2-3):73-93.

11. Dehnavi V. Surface Modification of Aluminum Alloys by Plasma Electrolytic Oxidation. [Thesis]. London: Western University; 2014.

12. Mécuson F, Czerwiec T, Belmonte T, Dujardin L, Viola A, Henrion G. Diagnostics of an electrolytic microarc process for aluminium alloy oxidation. Surface and Coatings Technology. 2005;200(1-4):804-808.

13. Hussein RO, Zhang P, Nie X, Xia Y, Northwood DO. The effect of current mode and discharge type on the corrosion resistance of plasma electrolytic oxidation (PEO) coated magnesium alloy AJ62. Surface and Coatings Technology. 2011;206(7):19901997.

14. Dehnavi V, Luan BL, Shoesmith DW, Liu XY, Rohani S. Effect of duty cycle and applied current frequency on plasma electrolytic oxidation (PEO) coating growth behavior. Surface and Coatings Technology. 2013;226:100-107.

15. Marcomini RF, Souza DMPF. Microstructural characterization of ceramic materials using the image digital processing software Image J. Cerâmica. 2011;57(341):100-105.

16. ASTM Intyernational. ASTM G173 - 03 - Standard Tables for Reference Solar Spectral Irradiances: Direct Normal and Hemispherical on $37^{\circ}$ Tilted Surface. West Conshohocken: ASTM International; 2012.

17. Fox M. Optical properties of solids. Oxford: Oxford University Press; 2001.

18. Fan Z, Yang J, Ding JN, Yuan NY. Influence of microstructured substrate on solar selective absorbing films. Surface Engineering. 2013;29(6):484-488.

19. Rentschler HC, Nagy R, Mouromseff G. Bactericidal Effect of Ultraviolet Radiation. Journal of Bacteriology. 1941;41(6):745774.

20. Synnefa A, Santamouris M, Akbari H. Estimating the effect of using cool coatings on energy loads and thermal comfort in residential buildings in various climatic conditions. Energy and Buildings. 2007;39(11):1167-1174. 